\title{
A PROMISSORA PROVÍNCIA PETROLÍFERA DO PRÉ-SAL
}

\author{
Alessandra Aloise de Seabra, Gilberto Passos de Freitas, Marcus Polette \\ e T. Ángel Del Valls Casillas
}

THE PROMISING OIL PROVINCE OF THE PRE-SALT

\section{RESUMO}

O DESAFIO NACIONAL A PARTIR DA DESCOBERTA DA PROMISSORA PROVÍNCIA PETROLÍFERA DO PRÉ-SAL É ESTABELECER PARÂMETROS QUE NORTEIEM UM DESENVOLVIMENTO SUSTENTÁVEL, COM RESPEITO AO MEIO AMBIENTE E ÀS POPULAC̄ōES LOCAIS. EM GERAL, OS PROBLEMAS DOS PAÍSES ABUNDANTES EM PETRÓLEO DECORREM DA DIFICULDADE NO GERENCIAMENTO DAS RENDAS DA PRODUCÃ̃. NESSE CONTEXTO, O PRESENTE ARTIGO CONSIDERA A APLICAÇÃO DOS ROYALTIES NA ZONA COSTEIRA DO PAÍS NECESSÁRIA E LEGÍTIMA. A PARTIR DE UMA METODOLOGIA ARGUMENTATIVA, ANALISOU-SE A CONCENTRAÇÃO DA ATIVIDADE PETROLIFERA NA COSTA, A NATUREZA JURÍDICA DOS ROYALTIES, BEM COMO A ESTRUTURA LEGISLATIVA DA DIVISÃO DO RECURSO, A FIM DE CONTRIBUIR COM O DEBATE SOBRE O REARRANJO INSTITUCIONAL DESSA MATÉRIA. CONCLUI-SE QUE A DIVISÃO IGUALITÁRIA DOS RECURSOS PETROLÍFEROS SÓ É LEGÍTIMA APÓS A RETIRADA DA PARCELA REFERENTE À MITIGAÇÃO DOS IMPACTOS. ANTES DISSO, TAL DIVISÃo VIOLARIA OS PRINCíPIOS dA IgUaldade E do Poluidor-Pagador.

\section{PALAVRAS-CHAVE}

Royalties, Petróleo, Divisão equânime, Zona Costeira, PRÉ-SAL

\section{ABSTRACT}

THE NATIONAL CHALLENGE SINCE THE DISCOVERY OF THE PROMISING OIL PROVINCE OF THE PRE-SALT IS TO ESTABLISH PARAMETERS TO GUIDE SUSTAINABLE DEVELOPMENT, WITH RESPECT TO THE ENVIRONMENT AND LOCAL POPULATIONS. IN GENERAL, THE PROBLEMS OF OIL-ABUNDANT COUNTRIES ARISE FROM THE DIFFICULTY IN MANAGING INCOMES FROM THE OIL PRODUCTION. IN THIS CONTEXT, THIS STUDY CONSIDERS THE APPLICATION OF ROYALTIES IN THE BRAZILIAN COASTAL ZONE NECESSARY AND LEGITIMATE. THROUGH AN ARGUMENTATIVE APPROACH, THE CONCENTRATION OF OIL ACTIVITY ON THE COAST, THE LEGAL NATURE OF ROYALTIES, AND THE LEGISLATIVE FRAMEWORK REGARDING THE DIVISION OF THE RESOURCE WERE ANALYZED IN ORDER TO CONTRIBUTE TO THE DEBATE ABOUT THE INSTITUTIONAL REARRANGEMENT OF THE MATTER. IT COULD BE CONCLUDED THAT THE EQUAL DIVISION OF OIL RESOURCES IS LEGITIMATE ONLY AFTER REMOVAL OF THE PORTION RELATING TO MITIGATION OF IMPACTS. OTHERWISE, SUCH PARTITION WOULD VIOLATE THE PRINCIPLES of Equality and Polluter PAyer.

\section{KEYWORDS}

Royalties, Petroleum, Equitable Distribution, Coastal ZONE, PRE-SALT

\section{INTRODUÇÃO}

A partir da descoberta da promissora província petrolífera do pré-sal, a discussão em torno dos critérios de distribuição dos royalties vem agregando vozes em todo o cenário político e entre integrantes da sociedade civil organizada. O tema definitivamente entrou de forma central na agenda política nacional. Inspirados pela 
representatividade financeira dos royalties, parlamentares de todo o País lançam suas campanhas em defesa do suposto direito dos seus respectivos estados a essa renda, delineando um cenário que nos remete a uma releitura da campanha nacionalista de 1946, quando, infundidos pelo exemplo de Monteiro Lobato, partidos políticos de esquerda e movimentos sociais lançaram a campanha de rua em defesa do petróleo denominada "O Petróleo é nosso". Após setenta anos da descoberta da primeira jazida, por todo o país ecoam pronunciamentos e propostas legislativas que completam o slogan da campanha de 1946 afirmando: "Se o petróleo é nosso, os royalties também são".

O presente artigo pretende agregar ao debate sobre a divisão dos royalties - tema que é objeto do Projeto de lei n. 8.051/2010 - a discussão sobre a importância econômica e ecológica da zona costeira brasileira, bem como a responsabilidade de todos os estados e municípios do País pela conservação e uso dos recursos existentes nessa região, onde a atividade está instalada.

O presente artigo considera a aplicação dos royalties provenientes da exploração petrolífera offshore na zona costeira brasileira necessária e legítima. A necessidade se pretende demonstrar a partir da constatação da concentração da atividade nessa região, bem como da análise da importância ecológica e econômica desse bioma costeiro. A legitimidade da proposição será demonstrada através do entendimento da natureza jurídica do instituto royalties.

A estrutura legislativa dos atuais critérios de distribuição também será analisada. Em seguida, discorreremos sobre a proposta de divisão equânime dos royalties - já que as participações especiais foram extintas pela Lei n. $12.351 / 10^{1}$ - propondo ao final que a alteração legislativa em análise no Congresso determine dispositivo discriminando o percentual dos royalties com vinculação às vertentes ambiental, social e econômica, a ser aplicado na zona costeira.

\section{O PRÉ-SAL}

A partir da Lei n. 9478/97 (Lei do Petróleo), a atividade passou a receber um novo impulso, aumentando de forma importante sua parcela no PIB nacional. Em 2007, com a descoberta dos reservatórios do pré-sal na bacia de Santos, no estado de São Paulo, tivemos deflagrada uma nova realidade das reservas petrolíferas brasileiras. Passados treze anos da promulgação da Lei do Petróleo, o PIB do setor cresceu de $5,5 \%$ para $12 \%$ da economia nacional, alcançou a autossuficiência no abastecimento interno e tem no pré-sal a possibilidade de tornar o País um dos maiores exportadores da commodity no mundo.

Com uma área total de 149.000 quilômetros quadrados, a província do pré-sal é considerada a maior descoberta de petróleo do hemisfério sul nos últimos trinta anos, e aponta o País para um salto da décima quinta posição para a quarta no seleto 
ranking das dez maiores jazidas do mundo, colocando o Brasil no radar dos investidores internacionais (Petrobras, 2011a).

A formação geológica chamada de pré-sal é assim conhecida por estar coberta por uma camada de cerca de 2.000 metros de sal marinho depositado no leito oceânico. Está situada sob três bacias petrolíferas: Campos, Espírito Santo e Santos, onde foram realizadas as maiores descobertas na área até então.

As mais importantes reservas estão sob essa camada de sal, formada há 100 milhões de anos, no período de separação dos continentes americano e africano (Petrobras, 2011a).

A Província petrolífera do pré-sal representa um verdadeiro tesouro energético equivalente a cerca de 50 bilhões de barris de petróleo (Ajuris, 2009). A principal descoberta até o momento é protagonizada pelo gigantesco poço de Libra, situado a 183 quilômetros da costa do Rio de Janeiro, com um volume recuperável de óleo que pode variar entre 3,7 e 15 bilhões de barris, sendo a estimativa mais provável de 7,9 bilhões de barris.

É importante destacar que somente esse prospecto de Libra pode vir a ter um volume de óleo recuperável superior às atuais reservas provadas brasileiras, próximas de 14 bilhões de barris de petróleo, tornando-se dessa forma a maior descoberta de petróleo no mundo desde 2000, quando o Cazaquistão identificou 17,2 bilhões de barris na área de Kashagan (ANP, 2011).

Na bacia de Santos e na bacia do Espírito Santo também há importantes reservas como, Tupi, cuja estimativa é de 5 a 8 bilhões de barris; Iara, com estimativa de 3 a 4 bilhões de barris; e Parque das Baleias, com expectativa de 1,5 a 2 bilhões de barris de óleo equivalente. O óleo já identificado apresenta características de um petróleo de alta qualidade e maior valor de mercado (Petrobras, 2011a).

A mais recente descoberta foi anunciada em janeiro de 2011, no poço informalmente denominado Carioca Nordeste, onde também foi encontrado um óleo leve de boa qualidade (Petrobras, 2011b).

Os investimentos na província deverão ser altíssimos, em função da profundidade das reservas, o que exigirá a aplicação de tecnologia de alto custo. O caminho até o petróleo é longo, sendo preciso passar por 2 quilômetros de oceano e mais 1 quilômetro de rocha da camada pós-sal. Entretanto, o baixo risco exploratório, em um cenário internacional de relativa alta do preço do petróleo, parece viabilizar os custos de exploração e produção em águas ultraprofundas. O plano de negócios 2010-2014 da Petrobras prevê investimentos de US\$ 224 bilhões (Gabrielli et al., 2010).

Em 2 de setembro de 2008, foi efetuada a extração do primeiro óleo da camada pré-sal, através do navio-plataforma P-34 no Campo de Jubarte, na bacia de Campos, no Rio de Janeiro. Em $1^{\circ}$ de maio de 2009, deu-se início à produção de petróleo na descoberta de Tupi, por meio do Teste de Longa Duração (TLD) (Presidência da República, 2011). 
A partir do pré-sal, a Petrobras decidiu investir ainda mais pesado no segmento com a construção de refinarias, plataformas e navios, com recursos próprios ou com financiamentos de parceiros estrangeiros em todo o País. Acredita-se que, somente por volta de 2016 essas reservas estejam sendo exploradas em larga escala (Presidência da República, 2011).

Nos próximos anos, o Brasil produzirá, somente no pré-Sal já concedido (que corresponde a $28 \%$ do total da área) quase o mesmo volume produzido atualmente. Em 2009, a produção total média do primeiro semestre foi de $1.936 .000 \mathrm{barris} / \mathrm{dia}$, enquanto a estimativa de produção no pré-sal concedido para o ano de 2020 é de 1.815.000 barris/dia (MME, 2010).

Com grandes reservas, alta tecnologia em petróleo, base industrial diversificada, grande mercado consumidor e estabilidade institucional e jurídica, o País goza de uma situação privilegiada frente aos países que protagonizam o conflito de interesses petrolíferos (MME, 2010). Entretanto, essa riqueza potencial, concentrada em uma área de 800 quilômetros de extensão por 200 quilômetros de largura, traz consigo promessas e riscos, por suas gigantescas implicações econômicos, sociais, políticas e geopolíticas (Ajuris, 2009).

\section{I OPORTUNIDADE E DESAFIO}

A experiência internacional dos países exploradores de petróleo nos últimos quarenta anos mostra, em geral, um crescimento econômico inferior ao projetado, fraca diversificação econômica, altos níveis de pobreza e desigualdade, impactos ambientais devastadores no nível local, corrupção desenfreada, governança excepcionalmente insatisfatória, e grandes incidências de conflito e guerra (Tsalik et al., 2005).

A atividade petrolífera brasileira não pode se desenvolver alheia ao fato de estar instalada em uma área onde está concentrada cerca de $20 \%$ da biodiversidade mundial, com particular disputa de interesses em razão dos serviços prestados pelo ambiente costeiro, e com grande número de conflitos preexistentes, severamente potencializados pelo início da exploração.

A exploração do pré-sal não pode repetir os erros da bacia de Campos, onde o excesso de liberdade do administrador público na aplicação das verbas petrolíferas tem resultado em episódios de mal gasto de dinheiro público e suspeitas de corrupção (Aloise de Seabra, 2010).

O desafio agora é estabelecer um desenvolvimento que não seja predatório, especialmente para o ambiente costeiro e para as comunidades locais. A experiência nacional e internacional tem demonstrado que a propriedade de riqueza em recursos petrolíferos por si só não garante desenvolvimento socioeconômico, nem qualidade de vida para a população local.

A compensação dos impactos ambientais, sociais e econômicos gerados pela atividade deve ser priorizada na análise do gerenciamento das verbas, especialmente 
quando desenvolvida na zona costeira em razão da importância e da capacidade de resiliência dessa região.

Na busca pela sustentabilidade, é imprescindível o conhecimento da região efetivamente impactada, bem como o tipo e a extensão do impacto a fim de orientar a compensação.

Um estudo do Banco Mundial (2003) sobre os impactos da indústria petrolífera concluiu que a disponibilidade de petróleo representa tanto uma oportunidade como um desafio, e que a diferença entre a capacidade de colher mais ou menos benefícios dessa verdadeira “corrida do ouro" que aporta à região está nas forças econômica e cultural preexistentes no local.

Buscando identificar as áreas potencialmente impactadas pelo início da atividade no pré-sal, a Comissão Especial de Petróleo e Gás do Estado de São Paulo (Cespeg ) apresentou um prognóstico da atividade, indicando o perfil, a localização e o porte das novas atividades e dos investimentos da cadeia petrolífera na região. O relatório estima que a maior parte das exigências sobre as infraestruturas ocorrerão ao longo do litoral paulista, destacadamente entre os municípios de Itanhaém e Caraguatatuba. Investimentos como bases de apoio marítimo (supply houses), estaleiros para construção naval, canteiros de módulos e instalações empresariais de armazenagem e manutenção, dentre outros, estarão localizados nessa região (Cespeg, 2011).

O Estudo de Impacto Ambiental da atividade de perfuração marítima na bacia de Santos (EIA) definiu nos estados integrantes da bacia quais são os municípios nos quais a simples presença da atividade - devido ao aumento na arrecadação de impostos, fluxo migratório e/ou geração de empregos -, pode impactá-los econômica e socialmente. No estado do Rio de Janeiro temos os municípios de Niterói, Itaguaí e Rio de Janeiro; no estado de São Paulo, os municípios de Santos, Guarujá e Itanhaém; e no estado de Santa Catarina os municípios de Navegantes e Itajaí (Rima Bacia de Santos, 2010).

O desenvolvimento sustentável do setor é o grande desafio nacional. Entretanto, a enorme demanda por crescimento econômico e desenvolvimento social brasileiro, inerentes aos países em desenvolvimento, tornam a concretização dessa responsabilidade uma árdua tarefa.

A infraestrutura a ser instalada e a forma como a riqueza gerada será distribuída entre e nos municípios beneficiados nesse ciclo certamente serão um processo decisivo para o futuro ambiental, econômico e social do País, configurando inclusive uma nova dinâmica demográfica e geopolítica capaz de gerar um futuro incerto e paradoxal (Polette e Aloise de Seabra, 2011).

\section{I.2 ZONA COSTEIRA}

As zonas costeiras abrigam a maior parte da população mundial, cujas atividades estão direta ou indiretamente relacionadas aos serviços e bens ambientais proporcionados 
pelos ecossistemas litorâneos. De acordo com o Plano Nacional de Gerenciamento Costeiro II (PNGC II), pode-se afirmar que a sustentabilidade das atividades humanas nas zonas costeiras depende de um meio marinho saudável e vice-versa. A partir de diversos estudos, o plano enfatiza que "a saúde, o bem-estar e, em alguns casos, a própria sobrevivência das populações costeiras dependem da saúde e das condições dos ecossistemas costeiros" (MMA, 2011a).

A zona costeira brasileira é formada por cerca de 400 municípios segundo o PNGC II (MMA, 1998a), que representam cerca de 4,3\% (257.148 quilômetros quadrados) da área territorial do País onde vivem cerca de 45,5 milhões de habitantes, ou seja 23,9\% da população brasileira (Fig. 1). Enquanto a média de densidade média demográfica no Brasil é de 22,3 habitantes por quilômetro quadrado, os municípios litorâneos brasileiros apresentam uma densidade de 123 habitantes por quilômetro quadrado.

Figura 1. Evolução do crescimento populacional da zona costeira brasileira

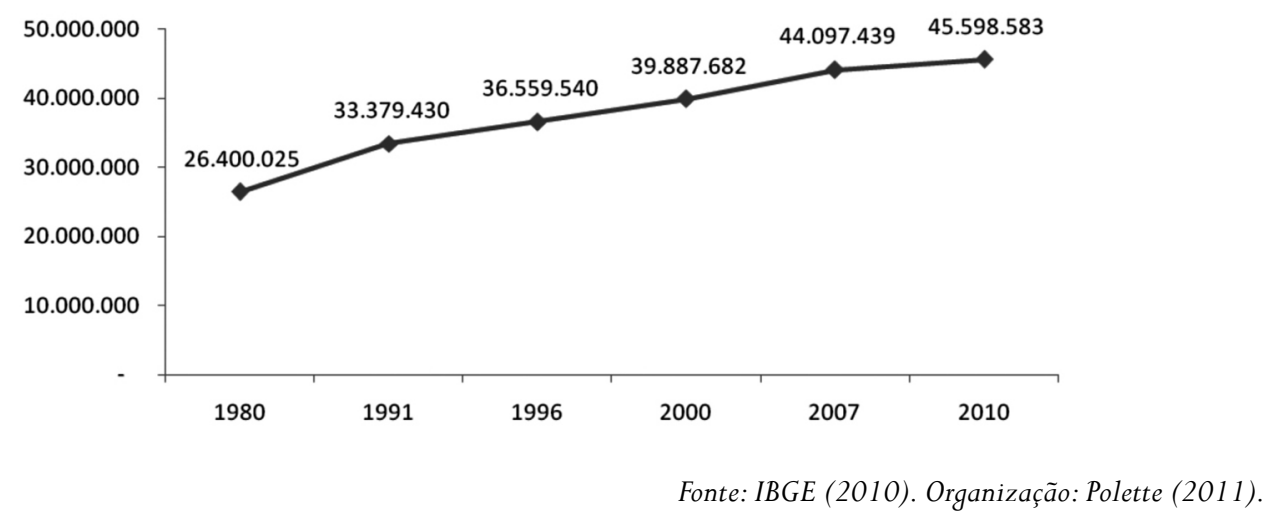

Em todo o mundo, a crescente e acelerada ocupação dessa área têm gerado conflitos entre a necessidade de preservação e de desenvolvimento (Castello et al., 2006).

\section{I.3 CONCENTRAÇÃo DA ATIVIDAdE PETROLÍFERA}

É em um ambiente com inúmeras pressões que atividade petrolífera se desenvolve. Noventa por cento das bacias petrolíferas estão localizadas na plataforma continental. Esse tipo de exploração (offshore) resulta na instalação de toda a cadeia petrolífera e parapetrolífera na região costeira adjacente aos campos de produção, e é essa indústria de apoio que provoca a maior parte dos impactos sociais, econômicos e ambientais nas regiões produtoras. São estruturas industriais, equipamentos de infraestrutura terrestre e portuária, escritórios de serviços, ou seja, 
os mais diversos tipos de empresas para atender à demanda por serviços e equipamentos da atividade.

Atualmente, estão localizadas na ZONA Costeira 9 das 10 bacias em atividade; 34 dos 37 terminais petrolíferos; 15 dos 18 gasodutos; 9 das 13 indústrias petrolíferas; e 10 das 17 termelétricas, como se vê na figura 2 (Petrobras, 2011c).

Figura 2. Mapa da atividade petrolífera

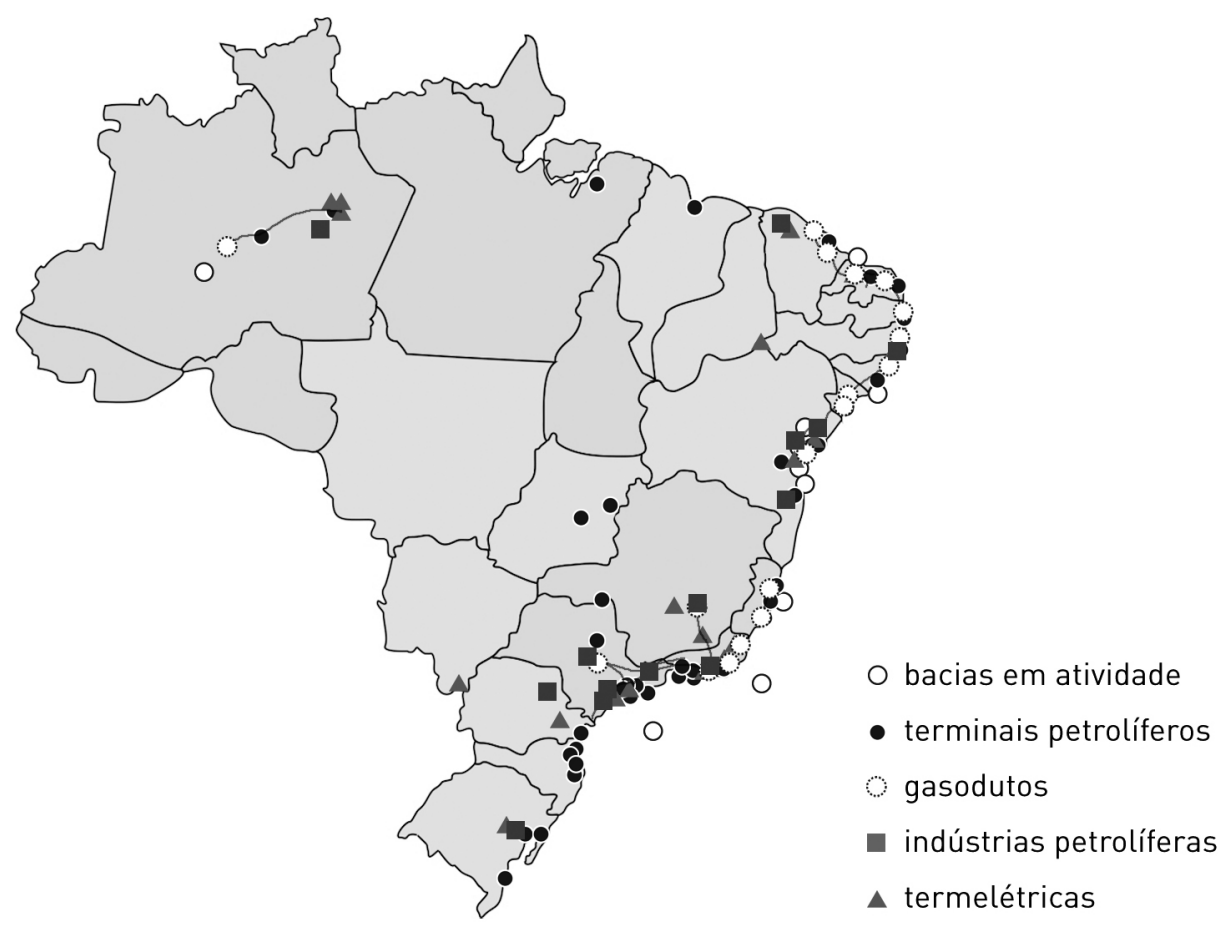

Fonte: Petrobras (2011c).

Um dos aspectos marcantes da atividade petrolífera é a celeridade do processo de crescimento das regiões onde ela é aportada. Como resultado dessa forte e repentina mobilização de capitais, a região agrega às suas dificuldades preexistentes os efeitos de uma intensa migração populacional, que normalmente resultam em segregação socioespacial e consequente favelização da comunidade pesqueira e dos migrantes que não conseguem trabalho; em guerra de lugares entre as prefeituras vizinhas - que disputam através da concessão de benefícios políticos (incentivos fiscais, leis de isenção) e técnicos (obras de infraestrutura) a atenção das empresas para 
os seus respectivos territórios; em especulação de vários mercados e na frequente alienação da população local frente aos benefícios da indústria petroleira.

$\mathrm{O}$ aporte quase instantâneo de pessoas físicas e jurídicas em grande número também desafia as administrações municipais da região a prover a necessária estrutura de bens e serviços públicos. A essa concentração, agregue-se o crescimento predatório gerado pelo acelerado processo de urbanização brasileiro. Em apenas meio século o Brasil - que era um país eminentemente rural - passou a ter $82 \%$ da sua população vivendo em cidades (Oliveira, 2001).

O desafio nacional a partir da descoberta desse importante tesouro energético que o pré-sal representa é estabelecer parâmetros que norteiem um desenvolvimento sustentável para o setor, com respeito ao meio ambiente e às populações locais. Nesse sentido, a importância da análise da região onde a atividade petrolífera está concentrada é um tema de grande importância.

\section{I.4 IMPORTÂNCIA ECOLÓGICA E ECONÔMICA DA REGIÃO}

A condição brasileira de abrigar entre 10 a $20 \%$ das espécies conhecidas coloca o País entre os mais biodiversos do mundo (MMA, 1998b). Um exemplo dessa significativa biodiversidade pode ser observado na Mata Atlântica, bioma que se estende por quase toda zona costeira do Brasil; ela representa a floresta mais rica do mundo em diversidade de árvores e abriga mais de 20 mil espécies de plantas, das quais 8 mil são endêmicas, ou seja, espécies que não existem em nenhum outro lugar no planeta. Comparada à Floresta Amazônica, proporcionalmente, a primeira apresenta a maior diversidade biológica. Trata-se do segundo ecossistema mais ameaçado de extinção do mundo, ela perde apenas para as quase extintas florestas da ilha de Madagascar na costa da África, e está reduzida a apenas $7,84 \%$ da sua área (Campanili et al., 2006).

O impacto que a biodiversidade representa na economia brasileira é extremamente alto. Somente o setor da agroindústria responde por cerca de $40 \%$ do PIB brasileiro, (calculado em US\$ 866 bilhões no ano de 1997); o setor florestal, 4;\%; e o pesqueiro, 1\%. Produtos da biodiversidade respondem por 31\% das exportações brasileiras, destas se destacam o café, a soja e a laranja (MMA, 2011b).

Cabe ressaltar que a geração de empregos também apresenta números importantes. As atividades de extrativismo florestal-pesqueiro empregam mais de três milhões de pessoas (MMA, 2011b).

Cerca de 30\% da matriz energética nacional utiliza a biomassa vegetal, contando o álcool da cana-de-açúcar, além da lenha e do carvão derivados de florestas nativas e plantadas. No nordeste, esse número chega a 50\% (MMA, 2011b).

Em razão da rica biodiversidade, a zona costeira apresenta alto impacto na economia do brasileira. Os serviços prestados pelo ambiente costeiro - turismo, lazer, abrigo e proteção, navegação, exploração de recursos não vivos, aproveitamento de recursos energéticos -, representam cerca de 70\% do Produto Interno Bruto (PIB) Nacional, 
fundamentalmente pela existência de portos, que são os atores principais no desenvolvimento da atividade exportadora brasileira (Freitas, 2005).

A ordem constitucional inaugurada em 1988 não admite mais o desenvolvimento de nenhuma atividade econômica a qualquer preço. A fim de orientar as atividades econômicas desenvolvidas na zona costeira e na Mata Atlântica, a Carta Magna, no parágrafo $4^{\circ}$ do art. 225, reconhece a importância ecológica e econômica desses biomas nacionais, outorgando-lhes a condição de Patrimônio Nacional e conferindo-lhes um regime jurídico particular. Essas regiões possuem regime diferenciado de autorização, de estudo de impacto e de conservação ambiental, exigindo que sua utilização esteja de acordo com a lei, dentro de condições que assegurem a preservação do meio ambiente, inclusive quanto ao uso dos recursos naturais.

A condição de Patrimônio Nacional conferida à zona costeira significa a ampliação dos limites de responsabilização pela conservação e uso sustentável dos recursos existentes nessa região. Originariamente adstrita aos territórios dos municípios costeiros, essa responsabilidade foi estendida a todos os municípios e estados do Brasil, através de comando constitucional, devendo a legislação infraconstitucional adequarse a essa realidade. Machado (2009) leciona que:

A regra geral constitucional tem sua importância não só por indicar ao administrador público, aos particulares e ao juiz que o desenvolvimento econômico não deve ser predatório, como torna claro que a gestão do litoral não interessa somente a seus ocupantes diretos, mas a todo brasileiro, esteja ele onde estiver, pois se trata de "patrimônio nacional".

Por todo o exposto, pode-se afirmar que a utilização dos royalties na respectiva região costeira impactada é necessária em razão da importância da área onde ela está instalada. Ademais, essa utilização não é feita em detrimento dos demais municípios brasileiros - como argumentam os que defendem a divisão igualitária do recurso -, pois a responsabilidade pela conservação dessa área, assim como os benefícios econômicos gerados a partir da utilização de sua rica biodiversidade, é de todos.

A legitimidade dessa proposição será a seguir desenvolvida a partir da análise da natureza jurídica dos royalties.

\section{NATUREZA JURÍDICA DOS ROYALTIES}

No direito brasileiro o termo royalty não tem origem constitucional. A positivação do termo veio através da legislação infraconstitucional sobre o tema. O que se convencionou denominar royalty é a "compensação financeira pela exploração de recursos naturais”, instituto respaldado pelo art. 20, $\S 1^{\circ}$, da Constituição Federal. 
Para a Agência Nacional do Petróleo, Gás Natural e Biocombustíveis (ANP), os royalties são uma compensação financeira atribuída aos concessionários de exploração e produção de petróleo e gás natural, a ser paga mensalmente pela empresa exploradora ao governo (art. 11, Decreto n. 2.705/98).

Manoel (2003) não reconhece a natureza compensatória do instituto. A natureza jurídica é definida pelo autor como "estipulação em favor de terceiros", um instituto do direito civil, onde dois entes contratam, e um terceiro, estranho ao contrato, é beneficiário daquele contrato, sendo possível a ambos exigirem a prestação devida pelo promitente.

O entendimento parte da premissa de que os bens do subsolo são de propriedade da União. Na condição de titular do bem explorado e, consequentemente, parte integrante do contrato de concessão realizado com a empresa exploradora de petróleo, o autor argumenta que a natureza jurídica compensatória somente existiria caso fosse a própria União a destinatária das verbas ora analisadas.

A premissa de que os bens do subsolo são de propriedade da União, contudo, é equivocada. A Constituição Federal de 1988 consagrou de forma nova e importante a existência de um bem que não possui características de bem público e, muito menos, privado. Nesse sentido, Costa (2008) ressalta o caráter inapropriável dos bens ambientais que em razão da sua natureza difusa possuem uma titularidade indeterminável, tendo em vista que pertence a todos.

Isso se deve ao art. 225 do texto constitucional: "Todos têm direito ao meio ambiente ecologicamente equilibrado, bem de uso comum do povo e essencial à sadia qualidade de vida, impondo-se ao Poder Público e à coletividade o dever de defendê-lo e preservá-lo para as presentes e futuras gerações”.

Os bens ambientais inauguram uma terceira espécie de bem, cuja titularidade não recai sobre qualquer dos entes federados. A partir da Constituição Federal de 1988, o art. 20, ao elencar os "os bens de propriedade da União", passa a receber interpretação diversa da literal. Em se tratando de bem ambiental, caberá à União a responsabilidade de gestão pelos bens ali elencados, uma vez que a propriedade passa a ser difusa.

Assim, a responsabilidade pela administração do petróleo, cuja natureza jurídica é a de bem ambiental, bem como o dever de prezar pela sua preservação, é da União, na qualidade de gestora e não de proprietária do bem.

A natureza compensatória dos royalties foi reconhecida pelo Supremo Tribunal Federal, através de manifestação nos autos do Recurso Extraordinário n. 228.8005/DF de 2001. O voto do então relator, ministro Sepúlveda Pertence, foi além e delimitou o pressuposto e a medida da obrigação do explorador: "Essa compensação financeira há de ser entendida em seu sentido vulgar de mecanismo destinado a recompor uma perda, sendo, pois, essa perda, o pressuposto e a medida da obrigação do explorador”(STF, 2001). 
O voto esclarece que a espécie de perda analisada no momento da destinação e cálculo dos royalties não se trata da perda do recurso mineral em si, pontuando: "A espécie de perda é aquela decorrente dos efeitos da exploração, dos problemas que acarreta a exploração dos recursos minerais sob tutela da lei”. Conforme decidido pela corte, os efeitos são aqueles de natureza ambiental, social e econômica.

Tal posicionamento, soberano por natureza, oferece a direção necessária para que tracemos o caminho rumo ao modelo de divisão e aplicação dos royalties, de tal forma que o instituto venha a atender a razão precípua de sua criação (Aloise de Seabra et al., 2008).

A natureza jurídica compensatória dos royalties também é defendida por Barroso (2010):

O conceito chave é o de compensação, seja pelo uso do território do Estado ou do Município, seja pelos danos ou ônus decorrentes da atividade. Pois bem: o que haveria para compensar em relação a uma região não envolvida nem afetada no processo de exploração? Caso todos os Estados e Municípios tivessem o mesmo direito, o local da atividade seria irrelevante e o emprego da palavra compensação não teria pertinência. O principal propósito do art. $20, \S 1^{\circ}$ da Constituição Federal é compensar os Estados e Municípios pelos impactos ambientais e socioeconômicos decorrentes de uma atividade de interesse nacional, proporcionando-lhes condições de prevenir riscos e de atender ao aumento da demanda por serviços públicos.

A natureza jurídica das participações governamentais também foi analisada por Leite (2009) que concluiu tratar-se de um instrumento de caráter compensatório cuja premissa não é baseada na utilização do bem, mas na compensação dos impactos ambientais, econômicos e sociais causados na respectiva região produtora.

\section{CRITÉRIOS ATUAIS DE DisTRIBUIÇÃO DAS VERBAS PETROLÍFERAS}

\section{I ESTRUTURA LEGISLATIVA}

$\mathrm{Na}$ legislação brasileira coexistem duas estruturas de distribuição dos royalties: uma para a parcela de 5\% e outra para a parcela excedente a 5\%. A ordem jurídica estabelecida pela Lei do Petróleo (Lei n. 9478/97) trouxe uma forma diferenciada de distribuição para a parcela acima de 5\% (inc. II, art. 49, da Lei n. 9478/97, regulamentada pelo Decreto n. 2.705/98).

Em relação à parcela de 5\%, a Lei n. 9478/97 remeteu à Lei n. 7.990/89 a disciplina da matéria. Essa legislação, por sua vez, estabelece o pagamento dos royalties através de uma alteração pontual no art. 27 da antiga Lei n. 2004/53. 
Ocorre que a Lei n. 2004/53 foi expressamente revogada pela própria Lei do Petróleo, conforme se depreende da análise literal do art. 83 da Lei n. 9478/97: "Art. 83. Revogam-se as disposições em contrário, inclusive a Lei n. 2.004, de 3 de outubro de 1953". Assim, constata-se que a parcela de 5\% dos royalties petrolíferos tem seus critérios embasados em legislação revogada desde 1997.

Vale ressaltar que o Projeto de lei 8.051/2010 tem como objeto o regime jurídico de distribuição de royalties sob o regime de partilha de produção. Dessa forma, persiste a lacuna legislativa para a parcela de 5\% dos royalties que seguirão sendo distribuídos sob o regime de concessão nas áreas já licitadas do pré-sal.

\subsection{PROPOSTA DE DIVISÃO EQUÂNIME DOS ROYALTIES}

Dentre os mais de 85 projetos de alteração dos critérios de distribuição dos royalties que estiveram em trâmite no Congresso Nacional Brasileiro, a proposta com base na divisão igualitária do recurso foi aprovada pelas duas Casas e encaminhada ao então presidente da República em 2010. $\mathrm{O}$ modelo redistribuía os royalties entre todas as unidades da federação sem considerar o critério de produção. A par da impropriedade técnica, por desconsiderar a razão de ser dos royalties, a divisão ainda estava baseada em legislação cuja inconstitucionalidade foi recentemente declarada pelo Supremo Tribunal Federal. ${ }^{2}$

Mencionada legislação foi editada em 1989 em obediência ao art. 159 da Constituição Federal sobre a repartição das receitas tributárias, mas deveria ter vigorado apenas nos exercícios fiscais de 1990 e 1992 . Após esse ano, a previsão era de que o censo do IBGE reorientaria a distribuição, mas isso nunca foi feito, resultando na inconstitucionalidade do dispositivo.

A proposta de divisão equânime dos royalties previa sua distribuição entre os Estados da Federação de acordo com o contexto socioeconômico do Brasil de 21 anos atrás, a partir de critérios ultrapassados.

Entretanto, a Lei n. 12.351/10 foi sancionada com veto ao art. 64 que disciplinava a matéria - a chamada Emenda Simon. A perspectiva para 2011 é a definição da alíquota dos royalties dos contratos de partilha e sua forma de distribuição, conforme Projeto de Lei n. 8.051/2010.

O Princípio da Igualdade, previsto no caput do art. 50 da Constituição Federal tem sido referenciado de forma corrente na defesa dessa repartição igualitária. Contudo, aludido princípio determina que seja dispensado um tratamento igual aos iguais, e desigual aos desiguais, na medida em que se desigualam.

Produções legislativas que dispensam um tratamento igual a todos, desconsiderando as diferenças, estarão viciadas, pois estão em desacordo com importante princípio 
constitucional. É partindo de um tratamento desigual com os desiguais que o legislador estará aproximando a sociedade da igualdade de fato.

Nesse sentido, Morais (2001) adverte que estão proibidos os tratamentos arbitrariamente desiguais. A arbitrariedade existirá quando não for possível encontrar uma razão qualificada para a diferenciação. O autor ressalta ainda que os tratamentos normativos diferenciados são compatíveis com a Constituição Federal, quando verificada a existência de uma finalidade razoavelmente proporcional ao fim visado.

É imperioso, portanto, que a um município costeiro onde se desenvolve a atividade petrolífera e a outro município sem nenhuma relação com a atividade sejam dispensados tratamentos desiguais, na medida da sua desigualdade, como medida de justiça.

$\mathrm{Na}$ discussão sobre a divisão igualitária dos royalties, outro importante princípio constitucional a ser analisado é o Princípio do Poluidor Pagador. O aludido princípio determina a internalização dos efeitos externos da atividade produtiva, os quais, passando a integrar os custos da produção, devem incidir diretamente sobre o lucro do produtor (Lima, 2003).

Como assinala Machado (2009), a atividade poluente acaba sendo uma apropriação pelo poluidor dos direitos de outrem, pois na realidade a emissão poluente representa um confisco do direito de alguém. O autor se refere ao confisco do direito constitucionalmente garantido à sociedade de usufruir de um meio ambiente saudável. A situação de iniquidade surge quando indivíduos assumem apenas os encargos da atividade poluidora, sendo excluídos de suas benesses.

Pode-se afirmar que uma vez descontada a parcela referente aos impactos, a divisão igualitária dos recursos petrolíferos passa a ser legítima. Antes disso, tal divisão implicaria em inobservância aos Princípios da Igualdade e do Poluidor Pagador.

A Lei n. 12.351/10 inaugura um novo modelo institucional da indústria petrolífera fundamentado no contrato de partilha de produção, onde a propriedade do petróleo extraído é exclusiva do Estado - em contraste com a propriedade exclusiva do concessionário, no caso da concessão. Nesse modelo, cabe ao contratado o exercício da atividade de exploração e produção à suas expensas, em troca de uma parte do petróleo extraído.

O contrato de partilha será aplicado nas áreas do pré-sal que ainda não foram licitadas e nas áreas consideradas de interesse estratégico, mantendo-se inalterado o regime da concessão nas demais áreas. As áreas ainda não licitadas correspondem a $72 \%$ do total da área do pré-sal, e as áreas consideradas de interesse estratégico correspondem às áreas em outras regiões do país nas quais, fora do pré-sal, eventualmente existam grandes reservas de petróleo (Confea, 2010).

Nesse ponto, convém salientar que a renda proveniente do pagamento dos royalties do petróleo representa apenas parte da renda total obtida com a exploração. No contrato de partilha, além das receitas governamentais (royalties e bônus de assinatura) e dos tributos incidentes, a União recebe ainda parcela do óleo produzido, 
garantindo a concretização do principal objetivo do governo com a alteração do regime de produção que é ter maior participação nos resultados da riqueza petrolífera nacional.

Além da parcela do óleo produzido, vale destacar que no Brasil essa atividade está sujeita ao pagamento de todos os impostos incidentes sobre as demais atividades econômicas. Trata-se de uma pesada carga tributária que, no ano de 2008, representou mais que o triplo de todas as participações governamentais somadas. Em impostos o setor arrecadou $\mathrm{R} \$ 77,87$ bilhões, enquanto em royalties e participações especiais a cifra foi de R\$22 bilhões (ANP, 2009).

Conforme salientado por Barroso (2010), o direito constitucional à compensação dos Estados e Municípios produtores (art. 20, $\S 1^{\circ}$ da Constituição Federal), não impede que os demais Estados-membros e Municípios recebam suas parcelas. A União pode repartir como quiser o seu próprio quinhão, mas ao distribuir a outros estados e municípios aquilo que cabe apenas aos produtores, estaria distribuindo o que não lhe pertence.

Isso significa que o respeito ao direito dos municípios costeiros, de ter a compensação dos impactos provocados pela atividade nos seus respectivos territórios, não se choca com o interesse nacional de investir no desenvolvimento social e no combate à pobreza.

\section{${ }_{4}$ CONSIDERAÇÕES FINAIS}

Por todo o exposto, conclui-se que a natureza compensatória dos royalties justifica sua utilização na respectiva região costeira adjacente aos campos de produção, desde que impactadas pela atividade. A finalidade dessa utilização está na recomposição dos impactos ambientais, sociais e econômicos ocasionados pela atividade exploradora. Ressaltamos a necessidade dessa compensação no caso brasileiro, em razão da importância ecológica e econômica da região costeira onde a atividade está instalada.

A vinculação dessa receita à compensação do respectivo impacto - ambiental, social e econômico - é um pressuposto essencial de sustentabilidade da atividade petrolífera, na medida em que direciona a correta aplicação da verba, diminuindo a liberdade do administrador público.

Num cenário promissor para a atividade petrolífera nacional, este artigo procura contribuir com o debate sobre o rearranjo institucional dessa matéria, destacando a importância da área na qual a atividade se desenvolve, bem como a responsabilidade nacional pela conservação dos recursos existentes nessa região. 


\section{NOTAS}

1 Lei n. 12.351/10. Estabelece um novo marco regulatório para a E\&P de petróleo, gás e outros hidrocarbonetos fluidos baseado na partilha de produção; além de criar um Fundo Social petrolífero vinculado à Presidência da República.

2 O modelo previa a utilização de percentuais do Fundo de Participação dos Estados e dos Municípios (FPE), art. $2^{\circ}$ da Lei Complementar 62/89.

\section{REFERÊNCIAS BIBLIOGRÁFICAS}

AJURIS. Associação dos Juízes do Rio Grande do Sul. Cartilha E o pré-sal é nosso? Ano I, n. 1, 2009.

ALOISE DE SEABRA, A,; FREITAS, G. P.; CONCEIÇÃO JUNIOR, O. P. A Justa Distribuição dos Royalties de Petróleo e Gás como Instrumento de Política Ambiental. Revista Ceciliana. Universidade Santa Cecília, 19, n. 30, p. 103-113, ago./dez., 2008.

ALOISE DE SEABRA, A. Necesidad y Legitimidad de la Aplicación de los "Royalties" del Petróleo en la Zona Costera de Brasil. EUROPEAN JOINT MASTER IN WATER AND COASTAL MANAGEMENT. UCA. Universidad de Cádiz, 2010.

ANP. Agência Nacional Petróleo. Superintendência de Planejamento e Pesquisa. Estimativa da Contribuição Tributária do Setor de Petróleo e Gás: 2002-2008. Nota Técnica ANP n. 22, 2009.

. Notas à Imprensa. Disponível em: http: / www.anp.gov.br/?pg=36488\&m=libra\&t1 =\&t2=libra\&t3 $=\& \mathrm{t} 4=\&$ ar $=0 \& p s=1 \&$ cachebust $=1297187033916$. Acesso em: 8 fev. 2011.

BANCO MUNDIAL. Mejores Prácticas para Hacer Frente a los Impactos Sociales de las Operaciones de Petróleo y Gas. Manejo de Las Rentas. 2003. Disponível em: http://www.worldbank.org/ogsimpact/mgroverviewsp.htm. Acesso em: 22 mar. 2008.

BARROSO, L. R. Federalismo, Isonomia e Segurança Jurídica Inconstitucionalidade das Alterações na Distribuição de Royalties do petróleo. Consulta formulada pelo Estado do Rio de Janeiro. Universidade do Estado do Rio de Janeiro, 2010

BRASIL. Lei n. 2.004, 3 out. 1953. Dispõe sobre a Política Nacional do Petróleo e define as Atribuições do Conselho Nacional do Petróleo, institui a Sociedade por Ações Petróleo Brasileiro Sociedade Anônima (Petrobras), e da outras providências. Disponível em: http://www.jusbrasil.com.br/legislacao/109500/lei-200453. Acesso em: 26 mai. 2011.

BRASIL. Constituição da República Federativa do Brasil, promulgada em 5 out. 1988.

BRASIL. Lei Complementar n. 62, 28 dez. 1989. Estabelece normas sobre o cálculo, a entrega e o controle das liberações dos recursos dos Fundos de Participação e dá outras providências. Disponível em:

http://www.planalto.gov.br/ccivil_03/constituicao/constitui\%C3\%A7ao.htm. Acesso em: 26 mai. 2011. BRASIL. Lei n. 7.990, 28 dez. 1989. Institui, para os estados, Distrito Federal e municípios, compensação financeira pelo resultado da exploração de petróleo ou gás natural, de recursos hídricos para fins de geração de energia elétrica, de recursos minerais em seus respectivos territórios, plataforma continental, mar territorial ou zona econômica exclusiva. Disponível em: http://www.jusbrasil.com.br/legislacao/103418/lei-7990-89. Acesso em: 26 mai. 2011.

BRASIL. Lei n. 9.478, 6 ago. 1997. Dispõe sobre a Política Nacional, as Atividades Relativas ao Monopólio do Petróleo, Institui o Conselho Nacional de Política Energética e a Agência Nacional do Petróleo (ANP) e dá outras providências. Disponível em: http://www.planalto.gov.br/ccivil_03/Leis/L9478.htm. Acesso em: 26 mai. 2011. BRASIL. Decreto n. 2.705, 3 ago. 1998. Define critérios para cálculo e cobrança das participações governamentais de que trata a Lei n. 9.478, 6 ago. 1997, aplicáveis de exploração, desenvolvimento e produção de petróleo e gás natural, e dá outras providências. Disponível em:

http://www.jusbrasil.com.br/legislacao/111637/decreto-2705-98. Acesso em: 26 mai. 2011.

BRASIL. Lei n. 12.351, 22 dez. 2010. Dispõe sobre a exploração e a produção de petróleo, de gás natural e de outros hidrocarbonetos fluidos, sob o regime de partilha de produção, em áreas do pré-sal e em áreas estratégicas; cria o Fundo Social (FS) e dispõe sobre sua estrutura e fontes de recursos; altera dispositivos da Lei n. 9.478, 6 ago. 1997; e dá outras providências. Disponível em: http://www.jusbrasil.com.br/legislacao/ 1026276/lei-12351-10. Acesso em: 26 mai. 2011.

BRASIL. Projeto de Lei n. 8.051/10. Dispõe sobre os royalties devidos em função da produção de petróleo, de gás natural e de outros hidrocarbonetos fluidos sob o regime de partilha de produção, em áreas do pré-sal e em áreas 
estratégicas, instituído pela Lei n. 12.351, 22 dez. 2010, para os estados, Distrito Federal, municípios e órgãos da administração direta da União, e dá outras providências. Disponível em: http://www.camara.gov.br/sileg/ integras/832082.pdf. Acesso em: 26 mai. 2011.

CAMPANILI, M. PROCHNOW, M. (Orgs.) Mata Atlântica, uma rede pela floresta. Brasília: RMA. 2006.

CASTELLO, J. P. et al. (Orgs.) Avaliação ambiental de estuários brasileiros: diretrizes metodológicas. Instituto do Milênio (MCT/PADCT/CNPq). Rio de Janeiro: Museu Nacional, 2006.

CESPEG. Comissão Especial de Petróleo e Gás do Estado de São Paulo. Petróleo \& Gás no Estado de São Paulo. Panoramas, Desafios e Políticas Públicas. Disponível em: http://www.desenvolvimento.sp.gov.br/infraestrutura/ cespeg//files/relatorio_final_cespeg_7mb.pdf. Acesso em: 11 fev. 2011.

CONFEA. Conselho Federal de Engenharia, Arquitetura e Agronomia. Propostas Para o Desenvolvimento Sustentável Brasileiro. 2010. Disponível em: http://www.confea.org.br/publique/media/ cadernodepropostasdesenvolvimento.pdf. Acesso em: 27 mai. 2011.

COSTA, B. S. Tutela Jurídica do Minério de Ferro como Bem Ambiental. Dissertação de Mestrado. Universidade Federal de Minas Gerais, 2008.

FREITAS, M. A. P. Zona Costeira e Meio Ambiente. Curitiba: Ed. Juruá, 2005.

GABRIELli, J. S.; BARBASSA, A. Plano de Negócios 2010-2014 da empresa Petrobras, 2010.

LEITE, F. R. D. As participações governamentais na indústria do petróleo sob a perspectiva do Estado-Membro: Importância econômica, natureza jurídica e possibilidade de fiscalização direta. Revista DireitoGV. São Paulo, p. 527-548, jul./dez., 2009.

LIMA, G. M. Aplicação do princípio do poluidor-pagador aos danos ambientais provocados pela indústria petrolífera. II CONGRESSO BRASILEIRO DE P\&D EM PETRÓLEO \& GÁS, 2003.

MACHADO, P. A. L. Direito ambiental brasileiro. 17, ed. rer., atual. e ampl. São Paulo: Malheiros Editores, 2009. MANOEL, C. O. Natureza Jurídica dos Royalties do Petróleo no Ordenamento Jurídico Brasileiro. Dissertação. Universidade Federal do Rio Grande do Norte. Centro de Ciências Sociais Aplicadas. Curso de Direito, 2003. MINISTÉRIO DO MEIO AMBIENTE. Plano de ação federal para a zona costeira do Brasil. Brasília/DF, 1998. 34 p. Primeiro Relatório Nacional para a Convenção sobre Diversidade Biológica. Ministério do Meio

Ambiente. Brasília/DF, 1998b. Plano Nacional de Gerenciamento Costeiro II. Disponível em:

http://www.mma.gov.br/estruturas/sqa_sigercom/_arquivos/pngc2_78.pdf. Acesso em: 27 mai. 2011 a. Secretaria de Biodiversidade e Florestas. Biodiversidade Brasileira. Disponível em:

http: / / www.mma.gov.br/sitio/index.php?ido $=$ conteudo.monta\&idEstrutura $=72 \&$ idMenu=2338. Acesso em: fev. 2011b.

MINISTÉRIO DAS MINAS E ENERGIA. Disponível em: http://www.mme.gov.br/mme. Acesso em: jan. 2010. MORAES, A. Direito Constitucional. 10. ed. São Paulo: Ed. Atlas, 2001.

OLIVEIRA, I. C. E. Estatuto da cidade: para compreender. Rio de Janeiro: Ibam/Duma, 2001. PETROBRAS. Atuação no pré-sal. Disponível em: http://www.petrobras.com.br/pt/energia-etecnologia/fontes-de-energia/petroleo/presal/. Acesso em: 3 fev. 2011a. . Disponível em: http://www.petrobras.com.br/ri/Show.aspx?id_materia= 7LxZGzFkKlYOMbMSkpB3Wg=. Acesso em: 11 fev. 2011b. fev. 2011c Disponível em: http://www.petrobras.com.br/pt/quem-somos/principais-operacoes/. Acesso em: 11

POLETTE, M. Os desafios urbanos na zona costeira brasileira frente às mudanças climáticas. No prelo. 2011. POLETTE, M.; ALOISE DE SEABRA, A. COASTAL GOVERNANCE IN BRAZIL: THE CHALLENGES OF PRESALT CYCLE. Polette, M. Aloise de Seabra, A. 2011. "Dimensión Ecológica para a el Desarrollo Social y Económico Sustentable”. In press. PRESIDÊNCIA DA REPÚBLICA FEDERATIVA DO BRASIL. O petróleo no Brasil. Disponível em: http: / /blog.planalto.gov.br/o-petroleo-no-brasil/. Acesso em: 8 fev. 2011.

RIMA. Relatório de Impacto Ambiental. Atividade de perfuração marítima na área geográfica da bacia de santos e termo de ajustamento de conduta da bacia de Santos. ICF Consultoria, 2010.

SUPREMO TRIBUnAL FEDERAL. RE 228.800-5/DF. Rel. Min. Sepúlveda Pertence. DJU 16 nov. 2001. TSALIK, S.; SCHIFFRIN, A. (Orgs.) Reportando o petróleo. Um guia jornalístico sobre energia e desenvolvimento. Revenue Watch. Open Society Institute. New York. Initiative for Policy Dialogue, 2005. 


\author{
Rua Isidoro José Ribeiro de Campos, 63/44
Ponta da Praia - 11030-490
Santos - SP - Brasil
alessandra.seabralalum.uca.es \\ Rua Isidoro José Ribeiro de Campos, 63/44
Ponta da Praia - 11030-490
Santos - SP - Brasil
alessandra.seabralalum.uca.es \\ Rua Isidoro José Ribeiro de Campos, 63/44
Ponta da Praia - 11030-490
Santos - SP - Brasil
alessandra.seabralalum.uca.es \\ Rua Isidoro José Ribeiro de Campos, 63/44
Ponta da Praia - 11030-490
Santos - SP - Brasil
alessandra.seabralalum.uca.es
}

Rua Carvalho de Mendonça, 44 - Sala 205 Encruzilhada - 11070-100 Santos - SP - Brasil gpassosfreitaslauol.com.br

Rua Uruguai, 458 Fazenda - 88302-202 Itajaí - SC - Brasil mpolettedunivali.br

Polígono Río San Pedro, s/n Puerto Real - 11510 Cádiz - España angel.vallslauca.es

\section{Alessandra Aloise de Seabra}

Doutoranda do Programa Erasmus Mundus "PhD in Marine and Coastal Management" UNIVERSIDADE DE CÁdIZ - ESPANHA.

Pesquisadora associada ao Núcleo de Pesquisa da Pós-Graduação em Direito da Universidade Católica de SANTOS

\section{Gilberto Passos de Freitas}

Professor Titular da Pós-Graduação (Mestrado) Universidade Católica de Santos (Unisantos)

\section{Marcus Polette}

Pesquisador e PROFESSOR do CEnTRO dE CIÊnCIAS Tecnológicas da Terra e do Mar, Oceanografia UNIVERSIDADE dO VALE dO ITAJAí (UnIVALI)

\section{T. Ángel Del Valls Casillas}

Profesor Catedrático da Facultad de Ciencias DEL MAR Y AMBIENTALES UNESCO/UNITWIN/WICOP UNIVERSIDAD DE CÁDIZ (UCA) 
